\title{
Spatiotemporal Trends of Malaria in Relation to Economic Development and Cross-Border Movement along the China-Myanmar Border in Yunnan Province
}

\author{
Xiaotao Zhao ${ }^{1,2}$, Weerapong Thanapongtharm ${ }^{3}$, Siam Lawawirojwong ${ }^{4}$, Chun Wei², Yerong Tang², Yaowu Zhou², \\ Xiaodong Sun ${ }^{2}$, Jestumon Sattabongkot ${ }^{5}$, Jaranit Kaewkungwal ${ }^{1, *}$ \\ ${ }^{1}$ Department of Tropical Hygiene, Faculty of Tropical Medicine, Mahidol University, Bangkok, Thailand; ${ }^{2}$ Yunnan Institute of Parasitic Diseases, Puer, \\ Yunnan, China; ${ }^{3}$ Veterinary Epidemiological Center, Bureau of Disease Control and Veterinary Services, Department of Livestock Development, \\ Bangkok, Thailand; ${ }^{4}$ Geo-Informatics and Space Technology Development Agency, Bangkok, Thailand; ${ }^{5}$ Mahidol Vivax Research Unit, Faculty of \\ Tropical Medicine, Mahidol University, Bangkok, Thailand
}

\begin{abstract}
The heterogeneity and complexity of malaria involves political and natural environments, socioeconomic development, cross-border movement, and vector biology; factors that cannot be changed in a short time. This study aimed to assess the impact of economic growth and cross-border movement, toward elimination of malaria in Yunnan Province during its pre-elimination phase. Malaria data during 2011-2016 were extracted from 18 counties of Yunnan and from 7 villages, 11 displaced person camps of the Kachin Special Region II of Myanmar. Data of per-capita gross domestic product (GDP) were obtained from Yunnan Bureau of Statistics. Data were analyzed and mapped to determine spatiotemporal heterogeneity at county and village levels. There were a total 2,117 malaria cases with $85.2 \%$ imported cases; most imported cases came from Myanmar (78.5\%). Along the demarcation line, malaria incidence rates in villages/camps in Myanmar were significantly higher than those of the neighboring villages in China. The spatial and temporal trends suggested that increasing per-capita GDP may have an indirect effect on the reduction of malaria cases when observed at macro level; however, malaria persists owing to complex, multi-faceted factors including poverty at individual level and cross-border movement of the workforce. In moving toward malaria elimination, despite economic growth, cooperative efforts with neighboring countries are critical to interrupt local transmission and prevent reintroduction of malaria via imported cases. Cross-border workers should be educated in preventive measures through effective behavior change communication, and investment is needed in active surveillance systems and novel diagnostic and treatment services during the elimination phase.
\end{abstract}

Key words: Malaria, spatiotemporal trend, economic development, cross-border movement, China-Myanmar border

\section{INTRODUCTION}

The heterogeneity and complexity of malaria involves the political and natural environments, socioeconomic development, transportation and cross-border movement, access to health care services, and vector biology, factors that cannot be changed in a short time [1-7]. This study aimed to assess the impact of 2 facets, economic growth and cross-border movement, in moving toward malaria elimination in the remaining highly endemic areas along the China-Myanmar border, in

- Received 24 September 2019, revised 2 March 2020, accepted 6 April 2020.

*Corresponding author (jaranit.kae@mahidol.ac.th)

() 2020, Korean Society for Parasitology and Tropical Medicine

This is an Open Access article distributed under the terms of the Creative Commons

Attribution Non-Commercial License (https://creativecommons.org/licenses/by-nc/4.0 which permits unrestricted non-commercial use, distribution, and reproduction in any

medium, provided the original work is properly cited. the border areas of Yunnan Province during its pre-elimination phase.

Several studies have noted that it is important to fully understand the complex pathways between poverty and malaria so as to develop effective strategies for sustainable malaria control [8-11]. One study on malaria and poverty suggested a potential bidirectional relationship: poverty as a cause of malaria and malaria as a cause of poverty. Poverty sustains the conditions in which malaria thrives, and malaria impedes economic growth and keeps communities in poverty [9]. Another study reviewing the published and grey literature on malaria and poverty reported that the quality of the literature examining this issue is highly variable, with many different measures of socioeconomic status [11]. In assessing the economic burden of malaria, 2 different approaches have typically been followed. i.e., the perspectives of microeconomics and macroeco- 
nomics. Microeconomics studies assess the direct costs of malaria prevention and treatment at individual, household, and health service levels, with or without the estimated indirect cost of lost work time. Macroeconomics studies assess the long-term economic growth and development of malaria at larger scale (e.g., provincial, country level) [9].

Studies at country level examining the gross domestic product (GDP) of poor countries have revealed that malaria impedes economic growth in these countries. The loss of GDP owing to malaria in Uganda during 2003 was equivalent to USD 11 million (about USD 0.43 per capita) whereas almost $1.1 \%$ of GDP (about USD 2.2 per capita) is devoted to dealing with malaria in Tanzania [9]. In China, Yunnan Province lags behind other provinces in social and economic development. Its GDP per capita ranks 29th of 31 provinces [12]. One study in Yunnan noted that poverty and malaria appear to have a clear inverse relationship, with residents living along the border experiencing greater degrees of poverty and malaria infection than those in other regions of this province [10].

The challenge of countries nearing malaria elimination is often owing to international borders with countries that have not yet achieved substantial reductions in malaria transmission [12]. Cross-border movement of infected individuals from endemic areas to neighboring countries has been recognized as a contributor to the spread of malaria in Asia and Africa [1,1315]. Cross-border malaria transmission and reintroduction is the main challenge for China as it shares 4,060 km of porous international borders with Greater Mekong Subregion (GMS) countries. The China-Myanmar border is particularly challenging owing to ongoing conflict on the Myanmar side of the border, resulting in uninterrupted disease transmission [16-22]. Yunnan faces a problem similar to most GMS countries in that border malaria is a major source of disease transmission, and malaria parasites are introduced via porous borders by highly mobile human populations [13,23-25]. In 2011-2013, imported malaria infections accounted for more than $70 \%$ of all cases of malaria in Yunnan [26-29]. Another threat of malaria introduction is owing to internally displaced persons (IDPs) from neighboring Myanmar, where the malaria situation is far worse than that in Yunnan $[30,31]$. The Technical Scheme of China Malaria Elimination defined malaria cases as "indigenous case" or "imported case". An imported case is a patient who diagnosed with malaria with a history of travelling to overseas malaria-endemic areas during the malaria-transmission season, and the onset of malaria symptoms was less than 1 month af- ter returning. An indigenous case is a patient whose malaria infection was acquired from local transmission by Anopheles mosquitoes within China, including malaria cases with no clear evidence of being imported from outside the country.

As malaria is considered to be related to poverty and economic inequality, and poverty is often an underlying factor for migration, the specific objectives of the present study were to examine the spatial and temporal trends of indigenous and imported cases of malaria in relation to economic growth (per capita GDP) in the 18 border counties of Yunnan Province during the malaria pre-elimination phase and rapid economic development in China during 2011-2016. In addition, the spatiotemporal patterns of malaria at hotspots in adjacent areas between Yingjiang County of China and the Kachin Special Region II (KSR II) of Myanmar was analysed to examine changes in the persistently high incidence of border malaria during the same period.

\section{MATERIALS AND METHODS}

\section{Study area}

Yunnan shares a long border with 3 malaria-endemic countries: Myanmar, Laos, and Vietnam. The study area in the present investigation refers to 18 border counties within Yunnan Province in China and one special region in Myanmar. The border area on the Myanmar side includes internally displaced populations fleeing war. The 18 counties along the ChinaMyanmar border in Yunnan share a 2,185-km land border. This area had an annual average total population of 4.8 million during the years 2011-2016. The elevation varies greatly, from $210 \mathrm{~m}$ to $4,878 \mathrm{~m}$. Cross-border trade, logging, quarrying, mining, and plantation work are frequent labor activities performed at the border regions, and it is difficult to manage these mobile populations of workers [10,32].

Specifically, the study explored adjacent areas in the 2 countries, Yingjiang County of China and the KSR II of Myanmar (Fig. 1). Yingiiang County is located in the western part of Yunnan Province and shares a 214.6-km border with Kachin State in western Myanmar. The county's land area is $4,429 \mathrm{~km}^{2}$ and features mountains and alluvial plains, with elevations ranging from $210 \mathrm{~m}$ to $3,404.6 \mathrm{~m}$. The climate is subtropical. Yingjiang County has 15 townships, 103 village committees, 1,148 natural villages, and a total population of 310,000. Nine townships border Myanmar. KSR II has a land area of about $287 \mathrm{~km}^{2}$ with a total population of around 60,000; most local 


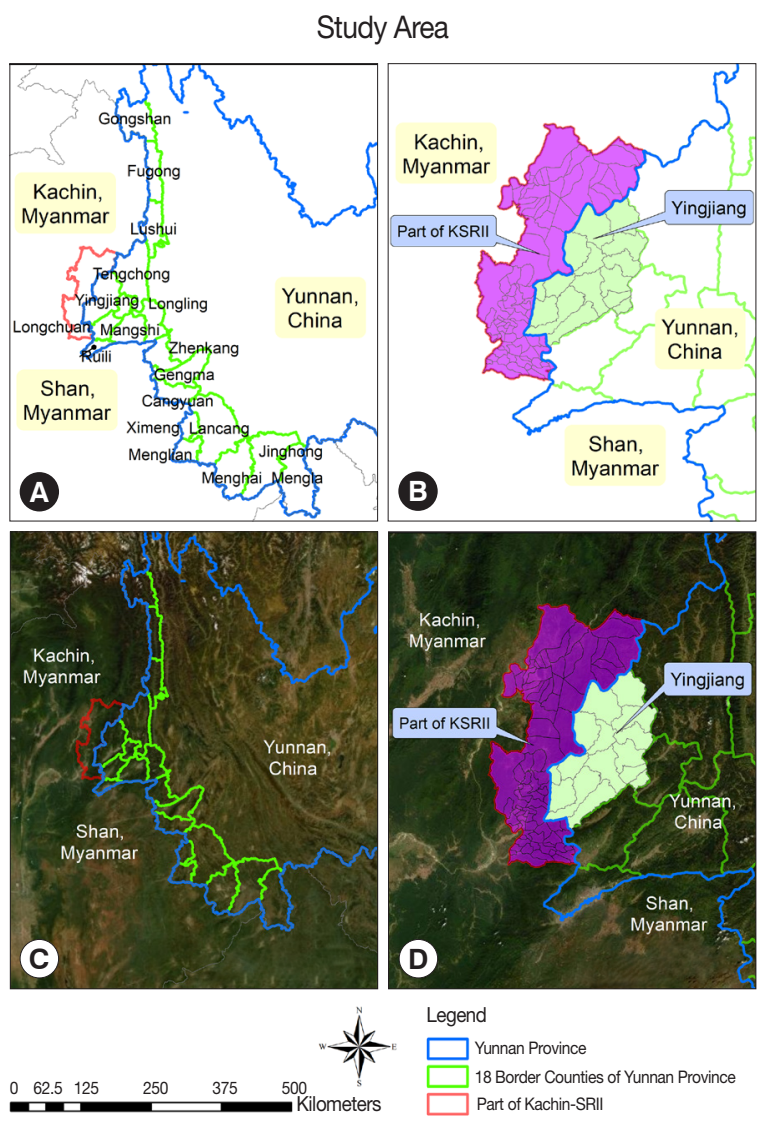

Fig. 1. Study area. (A) Map of counties at the China-Myanmar. (B) Map at demarcation line between Yingjiang county in China and KSRII in Myanmar. (C) Satellite image of 18 counties at the ChinaMyanmar border, (D) Satellite image at demarcation line between Yingjiang county in China and KSRII camp in Myanmar.

residents belong to the Kachin ethnic minority (known as Jinghpaw in China) $[18,33,34]$. Basic health care and malaria control activities have been established by the Kachin Independent Organization, which receives support from several international non-governmental organizations [12]. Since 2008, malaria prevention and control measures have been implemented in the KSR II including adequate treatment, bed-net distribution, and health education [34-36].

\section{Data source}

Malaria data were collected from 613 villages in the 18 border counties of Yunnan Province from 2011 to 2016; all villages reported cases of malaria during the study period. Data were obtained from China's National Notifiable Infectious Disease Reporting Information System, including individual case information and population data at county level. Population

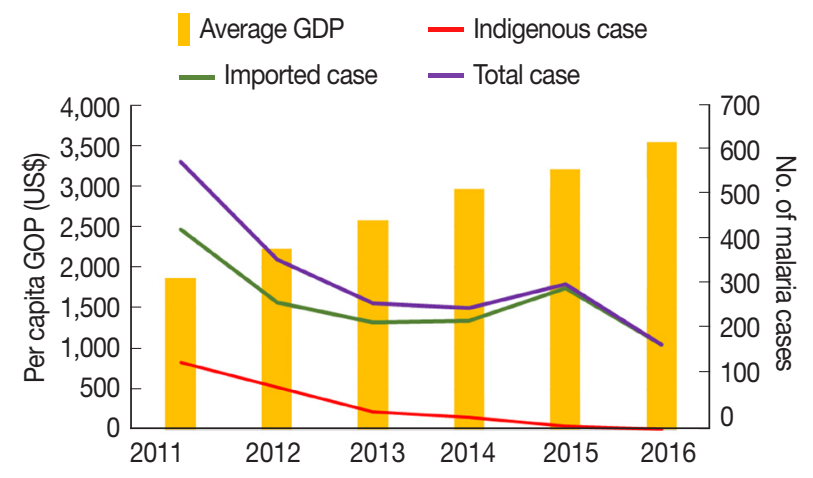

Fig. 2. Temporal trends of per capita GDP and malaria cases in 18 counties along the Yunnan border, 2011-2016.

data at village level were obtained from local governments on the China side. The data of per capita GDP in the 18 counties between 2011 and 2016 were obtained from the Yunnan Statistical Yearbook released by the Yunnan Bureau of Statistics.

Data from the Myanmar side were obtained from the malaria cooperative project between the Yunnan Institute of Parasitic Diseases (YIPD) and Health Poverty Action (HPA). Malaria data from Myanmar in this study were extracted from the malaria information system administrated by HPA and focused on only a partial area of the KSR II that borders all of Yingjiang County, with 7 villages and 11 IDP camps in the KSR II during 2014 to 2016.

\section{Data analysis}

Data on annual malaria cases from 2011 to 2016 were obtained exclusively at village level on the China side. Data were cross-validated by researchers and staff working in the local villages. The GDP data of 18 counties during the same study period were extracted from the official statistics released for Yunnan Province. The spatial and temporal distribution of malaria cases and GDP data at county and village levels were mapped using ArcGIS version 9 (Esri, Redlands, California, USA).

\section{RESULTS}

Spatial and temporal trends of malaria cases and GDP, 2011-2016

From 2011 to 2016, a total 2,117 cases of malaria were detected, treated, and reported in the 18 border counties. The number of confirmed indigenous and Myanmar-imported malaria cases in the 18 counties decreased from 2011 to 2016, as follows: $577,366,272,262,314$, and 184, respectively. On 

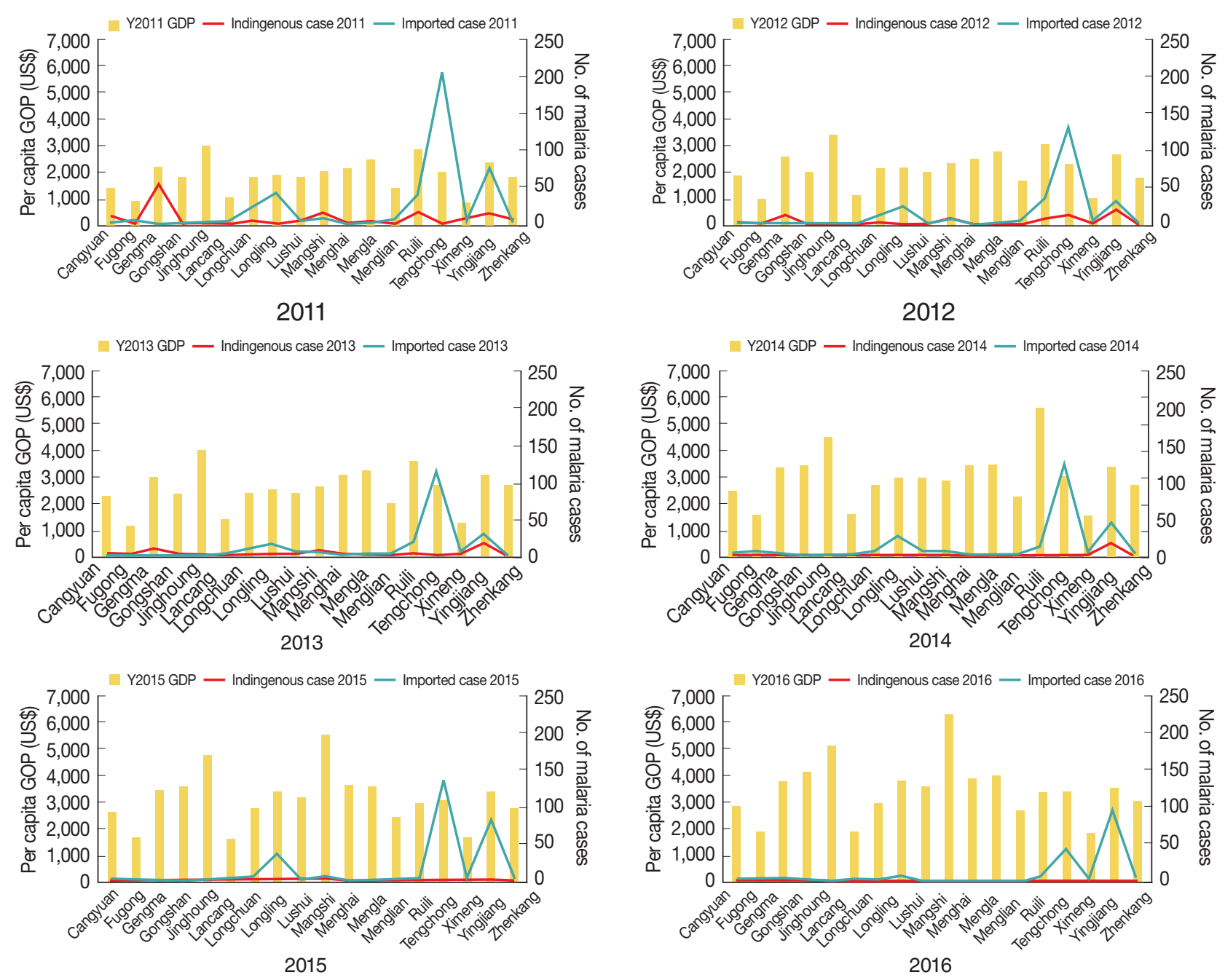

Fig. 3. Spatiotemporal malaria cases and per capita GDP of 18 counties along the Yunnan border, 2011-2016.

the contrary, average per capita GDP increased in the 18 counties over these 6 years, as follows: USD 1,868, 2,224, 2,583, $2,963,3,206$, and 3,533, respectively. Fig. 2 shows the opposite trends of malaria cases and GDP during the study period.

Overall, the number of malaria cases varied, with a general annual reduction at the county level. In 2016, 5 counties had no reports of malaria. High proportions of malaria $(89.4 \%$, $1,892 / 2,117)$ were generally concentrated in Tengchong, Yingjiang, Ruili, Longling, Gengma, Mangshi, and Longchuan counties, bordering the KSR I, KSR II, and Shan Kokang SR in Myanmar. Spatial and temporal trends of malaria cases and GDP by county are shown in Fig. 3. Whereas GPD showed increasing trends in all 18 counties over the 6 years, malaria cases appeared to decrease but were persistent in the aforementioned counties. Those counties with a high number of malaria cases during the study period had neither very high nor very low GDP.

\section{Spatial and temporal trends of malaria cases and source of infection, 2011-2016}

Of the 2,117 reported cases of malaria, a total 314 (14.8\%) were indigenous cases, with a drastic decreasing trend over the 6 years of the study period, from 145 cases in 2,011 to 1 case in 2016 (Table 1). A total 1,803 (85.2\%) cases were imported, of which 1,661 (78.5\%) were among Chinese citizens returning from Myanmar. The numbers of imported cases from Myanmar also declined but remained high, dropping from 432 in 2011 to 183 in 2016. From 2011 to 2016, the geographic distribution of indigenous malaria cases, which was aggregated in the central part of the border area, diminished continuously (Fig. 4). At county level, the annual number of indige- 
Table 1. Proportion of malaria cases by infection source in 18 counties, Yunnan bordering with Myanmar, 2011-2016

\begin{tabular}{|c|c|c|c|c|c|c|c|c|}
\hline \multirow[b]{2}{*}{ Year } & \multirow[b]{2}{*}{ Total } & \multirow[b]{2}{*}{ Indigenous } & \multicolumn{6}{|c|}{ Imported (\%) from } \\
\hline & & & Myanmar & Africa & Laos & Cambodia & Thailand & $\begin{array}{c}\text { Other place } \\
\text { in China }\end{array}$ \\
\hline 2011 & 642 & 145 (22.6) & 432 (67.3) & $1(0.2)$ & $4(0.6)$ & $1(0.2)$ & - & $59(9.2)$ \\
\hline 2012 & 395 & 92 (23.3) & $274(69.4)$ & $1(0.3)$ & $14(3.5)$ & - & - & $14(3.5)$ \\
\hline 2013 & 294 & 40 (13.6) & 232 (78.9) & - & 17 (5.8) & - & - & $5(1.7)$ \\
\hline 2014 & 269 & $27(10.0)$ & $235(87.4)$ & - & $4(1.5)$ & - & $2(0.7)$ & $1(0.4)$ \\
\hline 2015 & 321 & $9(2.8)$ & 305 (95.0) & - & $4(1.3)$ & - & $2(0.6)$ & $1(0.3)$ \\
\hline 2016 & 196 & $1(0.5)$ & 183 (93.4) & $4(2.0)$ & $8(4.1)$ & - & & - \\
\hline Total & 2,117 & $314(14.8)$ & 1,661 (78.5) & $6(0.3)$ & $51(2.4)$ & $1(0.1)$ & $4(0.2)$ & $80(3.8)$ \\
\hline
\end{tabular}

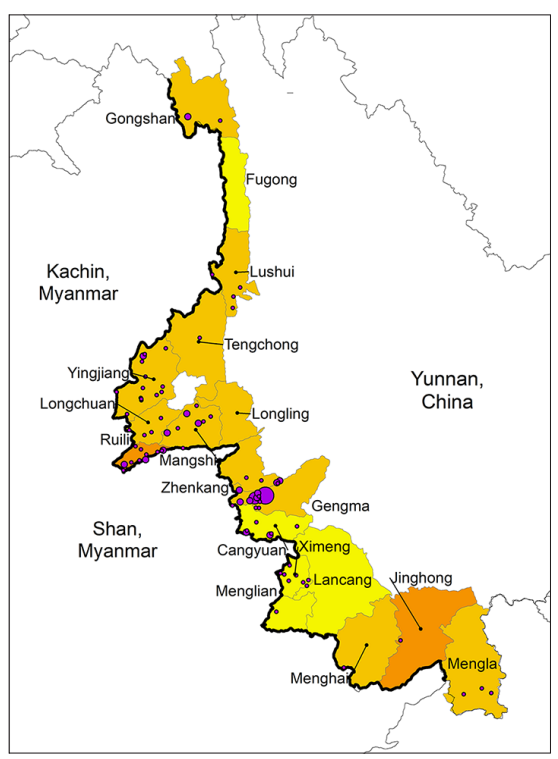

2011

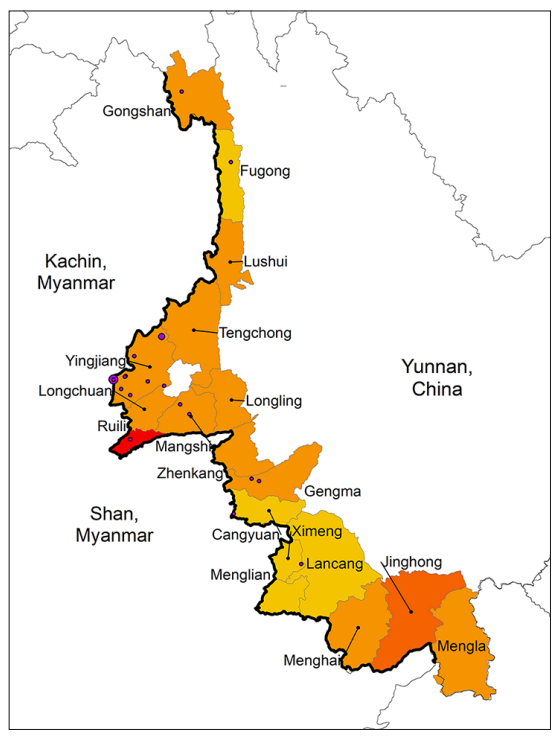

2014

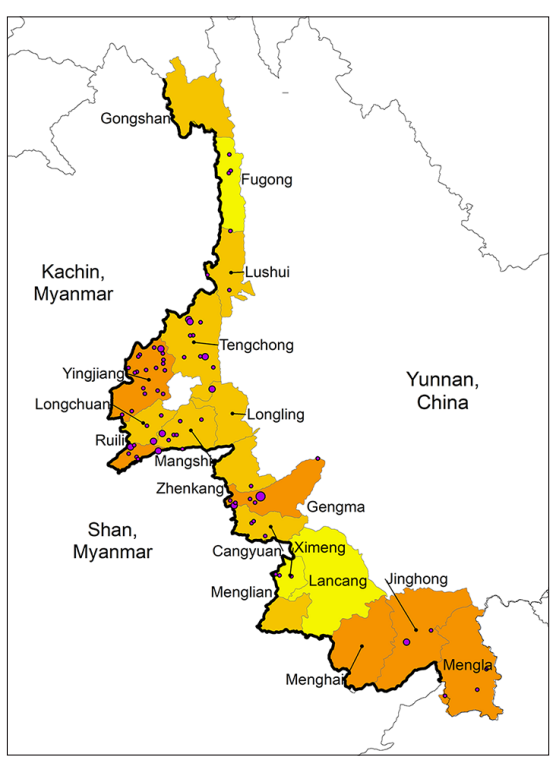

2012

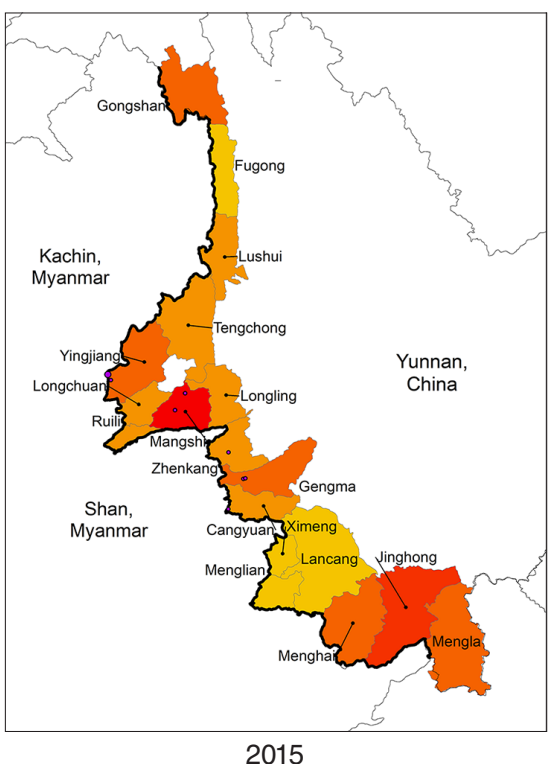

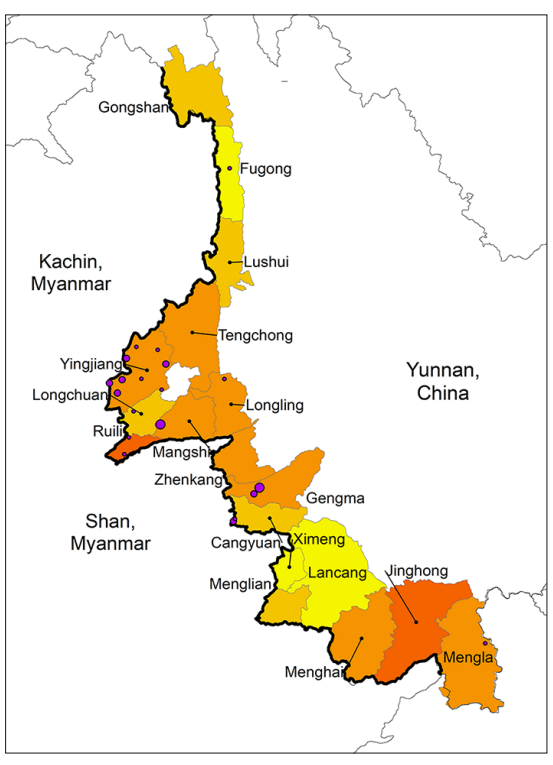

2013

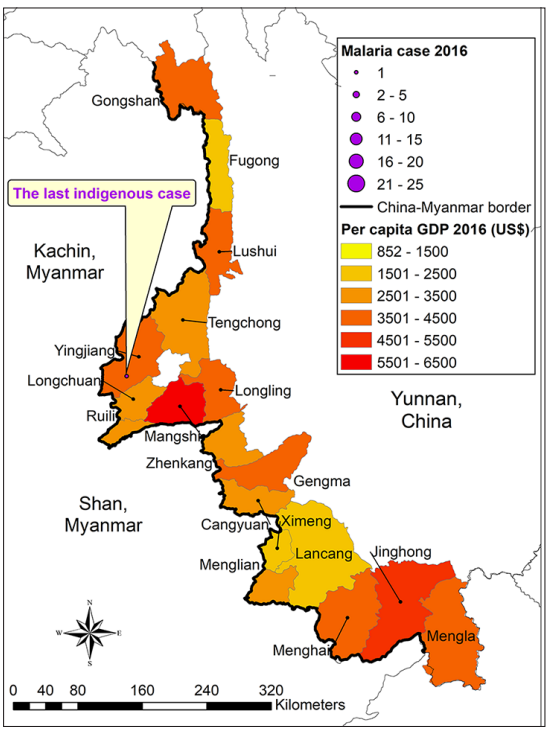

2016

Fig. 4. Spatiotemporal distribution of per capita GDP and indigenous malaria cases in 18 counites along the Yunnan border, $2011-2016$. 

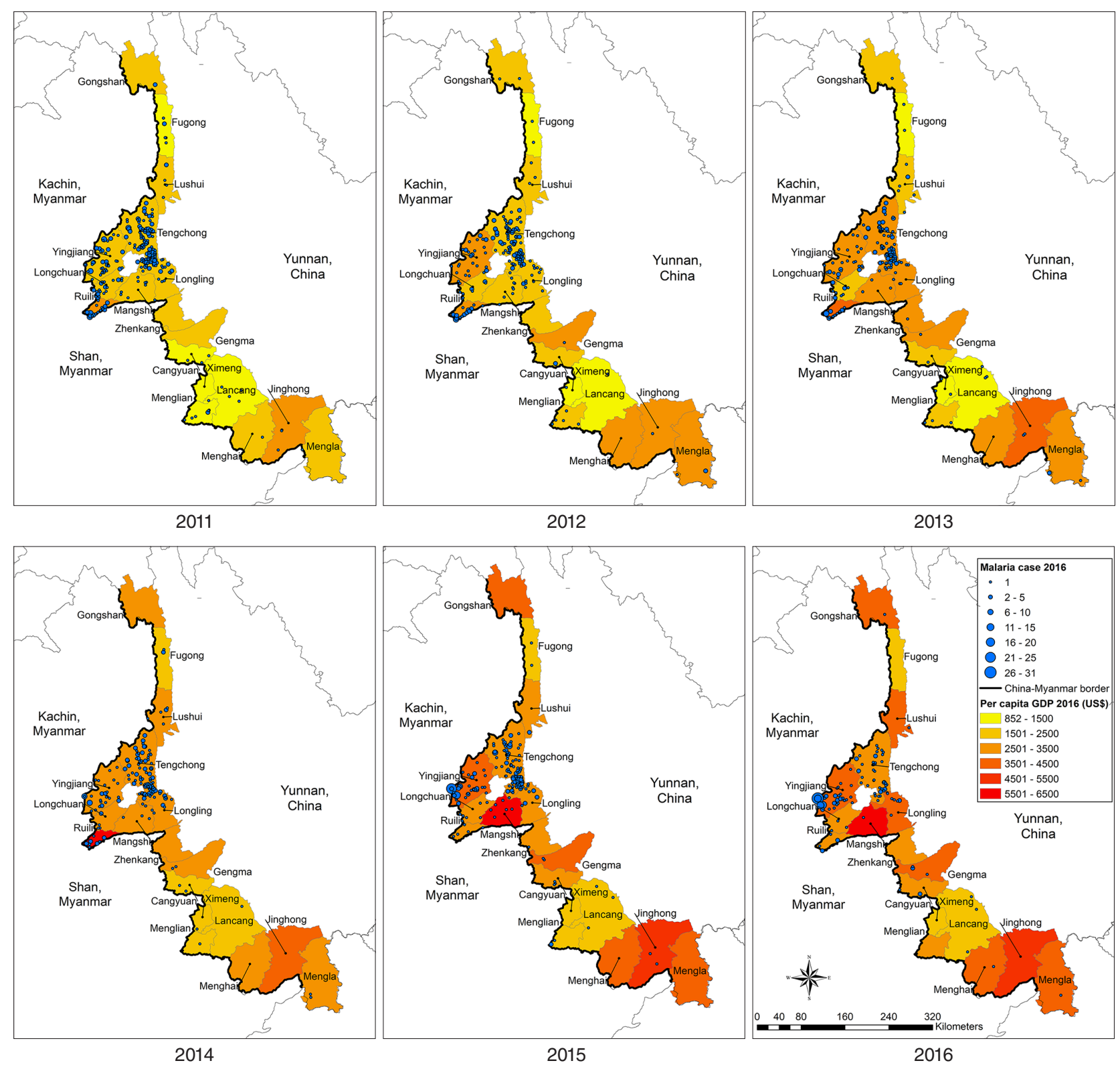

Fig. 5. Spatiotemporal distribution of per capita GDP and malaria cases imported from Myanmar in 18 counties along the Yunnan border, 2011-2016.

nous cases was 145 (14 counties), 92 (14 counties), 40 (9 counties), 27 (8 counties), 9 (5 counties), and 1 (1 county) during the reporting period. Only 1 case was reported in Yingiiang County in 2016. Similar to indigenous cases, imported malaria cases were aggregated in the central part of the border area (Figs. 4, 5). The background color of the maps in Figs. 4, 5 represents per capita GDP; again, both indigenous and imported cases were clustered in counties in the central part of the study area, which had neither very high nor very low per capita GDP.
Spatial and temporal analysis of malaria cases along adjacent areas of Yingjiang County and part of the KSR II

To demonstrate the problematic cross-border situation, the area adjacent to the border between Yingjiang Country and the KSR II, where high numbers of malaria cases were reported over the 6-year study period. The yearly incidence by village and IDP camp (Table 2) and mapped incidence rates and kernel density of malaria cases in these villages and IDP camps (Fig. 6) illustrated that very high prevalence of malaria was concentrated at the cross-border area of the KSR II. Malaria in- 
Table 2. Malaria incidence (/1,000 person) in Yingjiang County and KSR II on either side the China-Myanmar border 2011-2016

\begin{tabular}{|c|c|c|c|c|c|c|c|c|c|}
\hline \multirow[b]{2}{*}{ Year } & \multicolumn{3}{|c|}{ Yingjiang county, China } & \multicolumn{6}{|c|}{ Part of KSR II, Myanmar } \\
\hline & $\begin{array}{c}\text { Case } \\
\text { (Village) }\end{array}$ & Population & Mean (95\% Cl) & $\begin{array}{l}\text { Case } \\
\text { (village) }\end{array}$ & Population & Mean $(95 \% \mathrm{Cl})$ & $\begin{array}{l}\text { Case } \\
\text { (IDP) }\end{array}$ & Population & Mean $(95 \% \mathrm{Cl})$ \\
\hline 2011 & $92(43)$ & 104,510 & $1.55(0.78-2.78)$ & - & - & - & - & - & - \\
\hline 2012 & $56(37)$ & 90,533 & $0.94(0.64-1.38)$ & - & - & - & - & - & - \\
\hline 2013 & $48(31)$ & 74,110 & $1.09(0.61-1.72)$ & - & - & - & - & - & - \\
\hline 2014 & $62(30)$ & 76,597 & $1.48(0.56-2.80)$ & $83(6)$ & 1,547 & 115.27 (44.59-197.09) & $427(7)$ & 17,267 & $21.31(8.62-34.75)$ \\
\hline 2015 & $91(29)$ & 75,653 & $2.92(0.81-5.87)$ & $70(7)$ & 1,352 & 156.41 (67.95-242.95) & $407(6)$ & 19,457 & $17.03(7.46-26.83)$ \\
\hline 2016 & $104(27)$ & 73,564 & $5.19(0.66-11.67)$ & $94(11)$ & 2,294 & $162.74(61.25-278.18)$ & $936(5)$ & 17,006 & 48.67 (11.40-95.03) \\
\hline
\end{tabular}

*No malaria data for the KSR II in 2011-2013 owing to data collection constraints.

KSR II, Kachin Special Region II; IDP, internally displaced person; Cl, confidence interval.
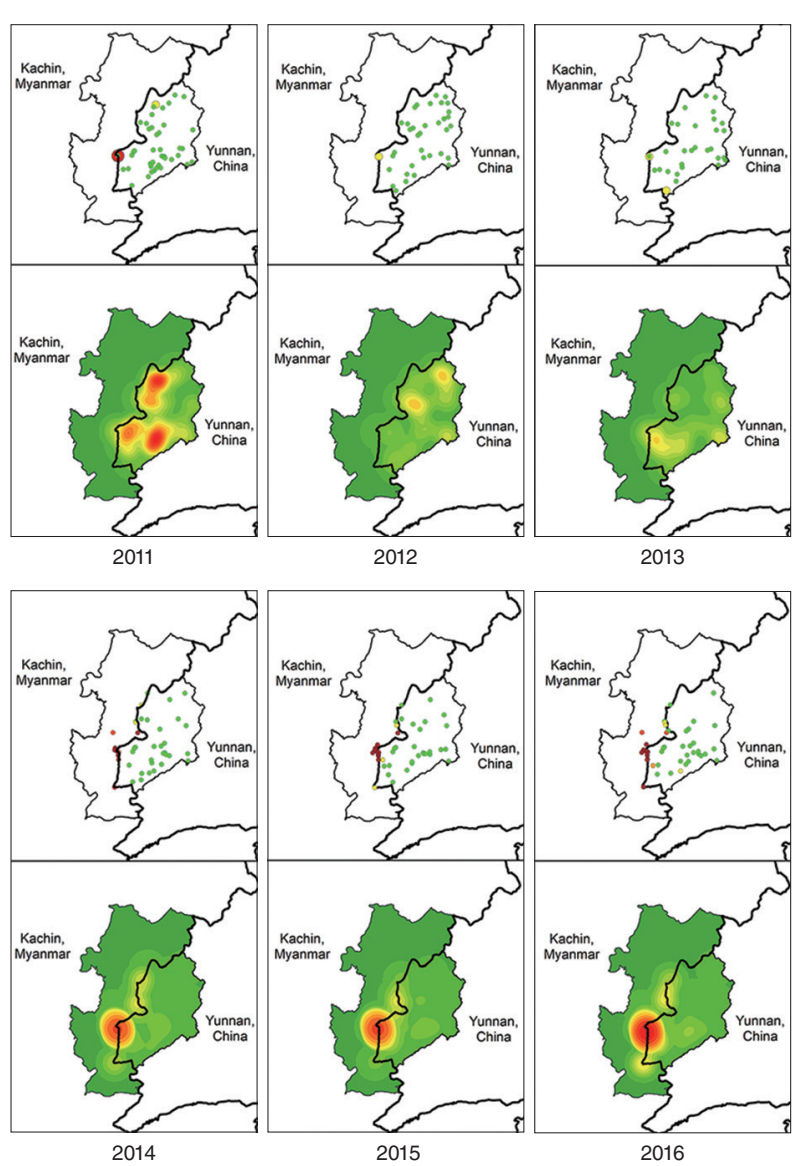

Fig. 6. Malaria Incidence along the China-Myanmar border area: Yingjiang County and part of the Kachin Special Region II (KSR II). *No malaria data for the KSR II in 2011-2013 owing to data collection constraints.

cidence rates in the Myanmar villages/IDP camps were significantly higher than those in neighboring villages on the China side. As shown by the kernel density of malaria cases during 2014-2016, hotspots were located at porous border-crossing points on both the China and Myanmar sides.

\section{DISCUSSION}

The heterogeneity and complexity of malaria epidemiology presents a challenge to the interruption of local malaria transmission. This study had assessed the spatiotemporal trends of malaria cases in relation to economic growth and cross-border movement over 6 years during the pre-elimination phase along the Yunnan border.

China has been successfully reducing gaps in socioeconomic development between urban and rural areas, especially remote mountainous regions, and between eastern and western regions of Yunnan [1]. A previous study suggested that malaria incidence in Yunnan during 2011-2016 had been significantly reduced, but transmission persists along the border and in poorer areas [37]. It was noted in another study that poverty may be a driver of malaria transmission in Yunnan, based on maps showing a spatial convergence of poverty and malaria incidence at county level [10]. The results of the present study confirmed the previous observation that the temporal distribution of malaria cases and economic growth showed an inverse trend: as per capita GDP increases, malaria cases decreased over the years. In contrast to that finding, when examining spatial patterns of the average annual GDP per capita at county level in Yunnan during 2011-2016, the results suggest an uneven distribution of economic status across the 18 border counties. When overlaying the spatial trends of malaria cases on GDP by county, no obvious pattern is visible; counties with a high number of malaria cases had neither very high nor very low GDP indices. Thus, caution must be used in drawing conclusions about the inverse relationship between malaria transmission and indices of economic development.

Since the launch of the National Malaria Elimination Program in 2010, through integrated strategies and activities, in- 
digenous cases of malaria have declined dramatically in Yunnan, particularly in the border area, with only 1 case reported in 2016 [36,38]. According to the national surveillance system, there have been no indigenous malaria cases reported in Yunnan since 2017, after the study period. The province thus declared the first zero report since the fight against malaria in China began [39]. About $85 \%$ of malaria cases in the study area were imported, similar to the proportion of imported cases reported in China during the past decade, at about $89 \%$ [30]. When mapping either indigenous or imported malaria cases together with GDP at county level, there again appeared to be no direct relationship between the 2 variables. More cases of malaria tended to be clustered in the middle part of the 18 counties, with GDP somewhat in the midrange between high and low GDP levels.

It is important to note that it may be difficult to determine whether an infected cases is indigenous or imported, since the incubation period varies depending on the strain of Plasmodium vivax. Individual immune status, prevention of medication, mixed infection, etc., can also affect the incubation period. Due to the climatic conditions and the history of local malaria epidemics in Yunnan, it is sometimes very difficult to determine the place of infection when a vivax malarian case occurs over 1 month after return from a malaria-endemic area outside the country. However, a previous study of malaria status from 2005 to 2012 showed meteorological factors--temperature, humidity, rainfall, and sunshine--did not show significant differences with malaria incidence per year, which also explained the conclusion that most malaria cases were imported [40]. I routine work in Yunnan Province, for cases of vivax malaria that occurred over 1 month after return, comprehensive investigation, analysis and judgment will be made in combination with histories of movement in/through malaria-endemic areas, preventive medication, malaria infection, malaria epidemic(s) in the patient's place of residence, and an investigation of Anopheles mosquitoes. Thus, vivax malaria cases that occur over 1 month after return, and with insufficient evidence to prove they are imported, will be treated as local infections. According to the WHO, in China, cases of vivax malaria will be followed for 3 years. The criteria are as follows: no indigenous case at any administration level for a consecutive period of 3 years if the county, municipality, or even the whole country, aim to achieve malaria elimination.

Economic growth may have an indirect effect on the distribution of malaria cases, as poverty and cross-border move- ment could be interrelated. With the development of China in recent years, increased economic prosperity and job opportunities may attract local people to work inside the country rather than abroad, thereby avoiding malaria infection while improving their income. On the other hand, those unable to find work locally may be compelled to become migrant workers seeking work such as logging, mining, planting, and road construction, by which could increase their income, but by working in high-risk areas of Myanmar, for example, where they work unprotected from malaria infection and are unable to access healthcare services. However, in the present study, most imported cases did not occur among laborers in very high GDP counties; most cases tended to occur in counties in the middle part of study areas during the 6-year study period. Imported cases of malaria are attributed to mass movement of mobile populations across international borders [29,41-43]. A study in Tengchong, a county in Yunnan with a high number of malaria cases, reported that migrant workers returning from Myanmar were the main contributor of imported malaria [44].

According to other surveys on imported malaria in the region, the distinctive characteristics of imported cases include adults, male sex, mainly engaged in agriculture, and labor-related travel history to other countries $[9,10,31,45]$. An analysis of the malaria epidemic situation in Tengchong, between 2010-2015, found that imported cases were mainly migrant workers who had returned from Myanmar. Malaria cases were reported in all towns and were clearly clustered with large numbers of migrant workers. The numbers of cases in AprilJune were higher than other periods, and the peak was inconsistent with the malaria-transmission season in Tengchong; instead, it was related to the return and number of migrants [46]. Tengchong County is adjacent to the Special Region of Kachin State in Myanmar, where degrees of malaria epidemic vary. Without natural barriers in most areas, there are many channels for entry and exit, and bilateral population flows are frequent. Such a setting makes this region a major source of malaria infection among migrant workers. The cross-border movement of imported cases into the central part of the 18 counties of Yunnan with high-to-midrange economic growth, rather than areas with the highest economic growth, might be based on workforce flows and the convenient adjoining border in that part of the province.

Political conflict is another underlying factor in cross-border movement and malaria cases. Specific spatial and temporal patterns of the malaria distribution in this study were illustrat- 
ed at the village/IDP camp level in Yingiiang County in Yunnan and in part of the KSR II in Myanmar along the border. Owing to the internal military conflicts on the Myanmar side of this region, residents have been evacuated from the inner part of the KSR II to villages and IDP camps situated very close to the border $[33,47]$. A previous study showed that the number of malaria cases and incidence rates in the villages and IDP camps on the Myanmar side were at least 8-fold higher than those in villages of neighboring Yingjiang County in China [17]. In this study, the average annual malaria incidence rates in local villages on the Myanmar side during 2014-2016 decreased to about 5-fold higher than those in IDP camps. The ongoing conflict not only undermines the public health infrastructure in Myanmar but also leads refugees from endemic areas with higher malaria rates to relocate to border areas $[17,48]$. The inevitable introduction of a large number of people with malaria infection, coupled with poor living conditions and a lack of malaria prevention efforts, undoubtedly increases the burden of malaria along these bilateral areas $[12,18,31,49]$. This finding also reflects a common challenge in that these 2 countries share a border and also share common malaria ecologies but are different in stages of the control-to-elimination pathway [50-52].

It is important to measure and quantify the relationship between poverty, cross-border movement, and the malaria burden at individual, community, county, country, and regional levels. Poverty or economic prosperity can be defined in many ways. Studies at individual or community level often define poverty indicators using a combination of household assets (housing type and ownership, education and sex of the head of household, and crowding in the household) or evidencebased indicators of socioeconomic status (occupation, transportation tools, income, expenditure or asset ownership, and rural location) $[8,11,49]$. For example, a study in Ghana found that social and economic factors are directly related to malaria morbidity, such that income levels for heads of household below the poverty line of USD 1 per day are a significant determinant of malaria morbidity [53]. A community-based study in Uganda reported that housing improvements and agricultural development to reduce poverty could be effective interventions against malaria [8]. At country level, a study in Saudi Arabia reported that increasing GDP had an impact on quality of life through urbanization, provision of higher education, and improved health care systems in the country; however, whereas low malaria incidence occurred during the period of rapid economic development, it was also coupled with aggressive local elimination strategies and cross-border collaboration [50]. This may be similar to the setting in Yunnan. As GDP increased in all counties together with more intensive efforts in reaching malaria elimination targets, the number of indigenous cases reached zero and imported cases were reduced. It is therefore difficult to quantify the impact of any single contributing factor among multi-faceted interventions. In moving toward elimination, consideration should not only be given to macroeconomic contributors but also to microeconomic development, as the distribution at larger scale may not be thoroughly covered at individual level, especially among the poor and the labor workforce at risk of malaria infection.

This study has a number of limitations. First, this study used data from government databases, which may be incomplete, and the variables were limited to what had been mandated for data collection. However, the research team compared data in the national databases against those from data sources at the local level, to ensure data quality. Second, the analysis was based on secondary data and some were aggregate data; thus, caution is needed in interpreting the results owing to the possibility of ecological fallacy. An inverse relationship might be observed at macro level but not at individual level. Third, the conceptual framework of the study was based on observation and an ecological study design; thus, it was unable to identify causal pathways linking economic development and crossborder movement with malaria cases in the study area. Fourth, GDP might be an imperfect index to represent poverty reduction over the years. Despite the aforementioned limitations, the spatiotemporal trend analyses in this study reflected changes in the patterns of indigenous and imported malaria cases in relation to changes in economic development in areas with persistence of endemic malaria along the Yunnan border. The findings will be useful in planning a framework for elimination.

In this study, over $90 \%$ of imported malaria cases were from Myanmar. Since there are no natural barriers along the ChinaMyanmar border, both people and mosquitoes easily cross the border. In many border communities, some households are Chinese and others Burmese, and they share the same mosquito breeding sites and mosquito species. For the reasons outlined above, it may be conjectured that the major malariainfecting species in the area are very similar (i.e., P. vivax and $P$. falciparum) and the proportion of people living on both sides of the border are infected similarly with both species of para- 
sites. This hypothesis regarding the high similarity of malariainfecting species along these border areas requires further investigation and validation.

It has been anticipated that Yunnan, particularly the border counties of the province, would be the final location in China of malaria elimination. However, the results of the present study showed that malaria has substantially decreasing during the pre-elimination phase (2011-2016). A remaining threat is imported cases in a number of counties adjacent to porous borders. The spatial and temporal trends shown in this study suggested that economic development may have an indirect effect on the reduction of malaria when observed from a macro-level perspective; however, malaria still persists owing to complex, multi-faceted factors including poverty at individual level and cross-border movement of the workforce. In moving toward malaria elimination, despite economic growth, cooperative efforts with neighboring countries are critical to not only interrupt local transmission but also to prevent reintroduction of malaria via imported cases. Cross-border workers should be educated in preventive measures through effective behavior change communication, and investment is needed in active surveillance systems and novel diagnostic and treatment services during the elimination phase.

\section{ACKNOWLEDGMENTS}

The data were collected (after obtaining permission and authorization) on both the China and Myanmar sides. This study was reviewed and approved by the Ethical Committee for Human Research of the Faculty of Tropical Medicine, Mahidol University and the Ethics Committee of the Yunnan Institute of Parasitic Diseases (YIPD) in China. The datasets used and/or analyzed during the current study are available from the corresponding author on reasonable request.

The researchers would like to acknowledge YIPD and the staff of prefecture and county level CDCs for their efforts and assistances in data collection.

\section{CONFLICT OF INTEREST}

The authors declare that they have no competing interests.

\section{REFERENCES}

1. Xu J, Liu H. The challenges of malaria elimination in Yunnan
Province, People's Republic of China. Southeast Asian J Trop Med Public Health 2012; 43: 819-824.

2. Xu X, Zhou G, Wang Y, Hu Y, Ruan Y, Fan Q, Yang Z, Yan G, Cui L. Microgeographic heterogeneity of border malaria during elimination phase, Yunnan Province, China, 2011-2013. Emerg Infect Dis 2016; 22: 1363-1370.

3. Yang D, Xu C, Wang J, Zhao Y. Spatiotemporal epidemic characteristics and risk factor analysis of malaria in Yunnan Province, China. BMC Public Health 2017; 17: 66.

4. Zhang Y, Liu QY, Luan RS, Liu XB, Zhou GC, Jiang JY, Li HS, Li ZF. Spatial-temporal analysis of malaria and the effect of environmental factors on its incidence in Yongcheng, China, 20062010. BMC Public Health 2012; 12: 544.

5. Zhou SS, Zhang SS, Wang JJ, Zheng X, Huang F, Li WD, Xu X, Zhang HW. Spatial correlation between malaria cases and waterbodies in Anopheles sinensis dominated areas of Huang-Huai plain, China. Parasit Vectors 2012; 5: 106.

6. Bi Y, Yu W, Hu W, Lin H, Guo Y, Zhou XN, Tong S. Impact of climate variability on Plasmodium vivax and Plasmodium falciparum malaria in Yunnan Province, China. Parasit Vectors 2013; 6: 357.

7. Xia J, Cai S, Zhang H, Lin W, Fan Y, Qiu J, Sun L, Chang B, Zhang Z, Nie S. Spatial, temporal, and spatiotemporal analysis of malaria in Hubei Province, China from 2004-2011. Malar J 2015; 14 : 145.

8. Tusting LS, Rek J, Arinaitwe E, Staedke SG, Kamya MR, Cano J, Bottomley C, Johnston D, Dorsey G, Lindsay SW, Lines J. Why is malaria associated with poverty? Findings from a cohort study in rural Uganda. Infect Dis Poverty 2016; 5: 78.

9. Teklehaimanot A, Mejia P. Malaria and poverty. Ann N Y Acad Sci 2008; 1136: 32-37.

10. Bi Y, Tong S. Poverty and malaria in the Yunnan province, China. Infect Dis Poverty 2014; 3: 32.

11. Worrall E, Basu S, Hanson K. Is malaria a disease of poverty? A review of the literature. Trop Med Int Health 2005; 10: 10471059.

12. Malaria Policy Advisory Committee Meeting. Evidence Review Group on Border Malaria [Internet]; Geneva, Switzerland: World Health Organization; [cited 2019 Aug 1]. Available from: https:// www.who.int/malaria/mpac/mpac-october2018-session6-border-malaria.pdf.

13. Cui L, Cao Y, Kaewkungwal J, Khamsiriwatchara A, Lawpoolsri S, Soe TN, Kyaw MP, Sattabongkot J. Malaria elimination in the Greater Mekong Subregion: challenges and prospects. In Manguin S, Dev V eds, Towards Malaria Elimination. London, UK. IntechOpen. 2018, pp 179-200.

14. Cui L, Yan G, Satabongkot J, Cao Y, Chen B, Chen X, Fan Q, Fang Q, Jongwutiwes S, Parker D, Sirichaisinthop J, Kyaw MP, Su XZ, Yang H, Yang Z, Wang B, Xu J, Zheng B, Zhong D, Zhou G. Malaria in the Greater Mekong Subregion: heterogeneity and complexity. Acta Trop 2012; 121: 227-239.

15. World Health Organization. Strategy for Malaria Elimination in the Greater Mekong Subregion (2015-2030) [Internet]; Geneva, Switzeland. World Health Organization.; [cited 2018 Jan 21]; 
Available from: http://iris.wpro.who.int/bitstream/handle/ 10665.1/10945/9789290617181_eng.pdf.

16. Zhang S, Zhang L, Feng J, Yin J, Feng X, Xia Z, Frutos R, Manguin S, Zhou S. Malaria elimination in the People's Republic of China: current progress, challenges, and prospects. In Manguin S, Dev V eds, Towards Malaria Elimination: A Leap Forward. London, UK. IntechOpen. 2018, pp 233-255.

17. Hu Y, Zhou G, Ruan Y, Lee MC, Xu X, Deng S, Bai Y, Zhang J, Morris J, Liu H, Wang Y, Fan Q, Li P, Wu Y, Yang Z, Yan G, Cui L. Seasonal dynamics and microgeographical spatial heterogeneity of malaria along the China-Myanmar border. Acta Trop 2016; 157: 12-19.

18. Chen T, Zhang S, Zhou SS, Wang X, Luo C, Zeng X, Guo X, Lin Z, Tu H, Sun X, Zhou H. Receptivity to malaria in the ChinaMyanmar border in Yingjiang County, Yunnan Province, China. Malar J 2017; 16: 478.

19. Yang HL, Xiao N, Yang YM, Xu JW. Challenges, opportunities and strategies of malaria elimination along China-Myanmar and China- Laos border. China Trop Med 2017; 17: 321-335.

20. Zhang Q, Sun J, Zhang Z, Geng Q, Lai S, Hu W, Clements AC, Li Z. Risk assessment of malaria in land border regions of China in the context of malaria elimination. Malar J 2016; 15: 546.

21. Wang D, Cotter C, Sun X, Bennett A, Gosling RD, Xiao N. Adapting the local response for malaria elimination through evaluation of the 1-3-7 system performance in the China-Myanmar border region. Malar J 2017; 16: 54.

22. Shi B, Zheng J, Qiu H, Yang GJ, Xia S, Zhou XN. Risk assessment of malaria transmission at the border area of China and Myanmar. Infect Dis Poverty 2017; 6: 108.

23. Hewit S, Delacollete C, Chavez I. Malaria situation in the Greater Mekong Subregion. Southeast Asian J Trop Med Public Health 2013; 44 (suppl): 46-72.

24. Lyttleton C. Deviance and resistance: Malaria elimination in the Greater Mekong Subregion. Soc Sci Med 2016; 150: 144-152.

25. Jitthai N. Migration and malaria. Southeast Asian J Trop Med Public Health 2013; 44 (suppl 1): 166-200.

26. Xia ZG, Yang MN, Zhou SS. Malaria situation in the People's Republic of China in 2011. Chin J Parasitol Parasit Dis 2012; 30: 419-422 (in Chinese).

27. Xia ZG, Feng J, Zhou S. Malaria situation in the People's Republic of China in 2012. Chin J Parasitol Parasit Dis 2013; 31: 413418 (in Chinese).

28. Zhou SS, Wang Y, Li Y. Malaria situation in the People's Republic of China in 2010. Chin J Parasitol Parasit Dis 2011; 29: 401-403 (in Chinese).

29. Wei C, Du LF, Zhao XT, Sun XD. Analysis of epidemic situation of malaria in Yunnan Province from 2011 to 2013Chin J Parasitol Parasit Dis 2016; 28: 26-29 (in Chinese).

30. Zhou SS, Wang Y, Fang W, Tang LH. Malaria situation in the People's Republic of China in 2008. Chin J Parasitol Parasit Dis 2009; 27: 455-456 (in Chinese).

31. Zhou G, Lo E, Zhong D, Wang X, Wang Y, Malla S, Lee MC, Yang Z, Cui L, Yan G. Impact of interventions on malaria in internally displaced persons along the China-Myanmar border: 2011-2014. Malar J 2016; 15: 471.

32. China.org.cn. Yunnan [Internet]; [cited 2018 Feb 10]. Available from: http://www.china.org.cn/e-xibu/2JI/3JI/yunnan/yunnanban.htm.

33. Song L. Refugees or Border Residents from Myanmar? The Status of Displaced Ethnic Kachins and Kokangs in Yunnan Province, China. Int J Refugee Law 2017; 29; 466-487.

34. Liu H, Xu JW, Bi Y. Malaria burden and treatment targets in Kachin Special Region II, Myanmar from 2008 to 2016: A retrospective analysis. PLoS One 2018; 13: e0195032.

35. Feng J, Liu J, Feng X, Zhang L, Xiao H, Xia Z. Towards malaria elimination: Monitoring and evaluation of the "1-3-7" approach at the China-Myanmar Border. Am J Trop Med Hyg 2016; 95: 806-810.

36. Xu JW, Li Y, Yang HL, Zhang J, Zhang ZX, Yang YM, Zhou HN, Havumaki J, Li HX, Liu H, Zhou H, Xie XY, Dong JX, Zhang Y, Sun XY, Li B, Li JY, Tian YH, Wang PY, Li BF. Malaria control along China-Myanmar Border during 2007-2013: an integrated impact evaluation. Infect Dis Poverty 2016; 5: 75.

37. Zhao X, Thanapongtharm W, Lawawirojwong S, Sattabongkot J, Wei C, Tang Y, Zhou Y, Li J, Kaewkungwal J. Spatio-temporal analysis of malaria cases along China-Myanmar border of Yunnan Province, 2011-2016. JTTMM Proceedings 2019; 8: 41-50.

38. Hui FM, Xu B, Chen ZW, Cheng X, Liang L, Huang HB, Fang LQ, Yang H, Zhou HN, Yang HL, Zhou XN, Cao WC, Gong P. Spatio-temporal distribution of malaria in Yunnan Province, China. Am J Trop Med Hyg 2009; 81: 503-509.

39. Feng J, Zhang L, Huang F, Yin JH, Tu H, Xia ZG, Zhou SS, Xiao N, Zhou XN. Ready for malaria elimination: zero indigenous case reported in the People's Republic of China. Malar J 2018; 17: 315.

40. Yang He-xian Lij. Correlation of malaria infection with the meteorological factors in Baoshan city from 2005 to 2012. Chin Trop Med 2014; 14: 289-292.

41. Liu Y, Hsiang MS, Zhou H, Wang W, Cao Y, Gosling RD, Cao J, Gao O. Malaria in overseas labourers returning to China: an analysis of imported malaria in Jiangsu Province, 2001-2011. Malar J 2014; 13: 29.

42. Wang D, Li S, Cheng Z, Xiao N, Cotter C, Hwang J, Li X, Yin S, Wang J, Bai L, Zheng Z, Wang S. Transmission risk from imported Plasmodium vivax malaria in the China-Myanmar Border Region. Emerg Infect Dis 2015; 21: 1861-1864.

43. Li Z, Zhang Q, Zheng C, Zhou S, Sun J, Zhang Z, Geng Q, Zhang H, Wang L, Lai S, Hu W, Clements A, Zhou XN, Yang W. Epidemiologic features of overseas imported malaria in the People's Republic of China. Malar J 2016; 15: 141.

44. Wang X, Yang L, Jiang T, Zhang B, Wang S, Wu X, Wang T, Li Y, Liu M, Peng Q, Zhang W. Effects of a malaria elimination program: a retrospective study of 623 cases from 2008 to 2013 in a Chinese county hospital near the China-Myanmar border. Emerg Microbes Infect 2016; 5: e6.

45. Yang D, Xu C, Wang J, Zhao Y. Spatiotemporal epidemic charac- 
teristics and risk factor analysis of malaria in Yunnan Province, China. BMC Public Health 2017; 17: 66.

46. Jia-Zhi W, Sheng-Guo L, Xi-Shang L, Zong-Yan T. Malaria epidemiological analysis in Tengchong City from 2010 to 2015. Chin J Schistosomiasis Control 2016. 28: 566-568 (in Chinese).

47. Xu JW, Liu H. The relationship of malaria between Chinese side and Myanmar's five special regions along China-Myanmar border: A linear regression analysis. Malar J 2016; 15: 368.

48. Wang RB, Dong JQ, Xia ZG, Cai T, Zhang QF, Zhang Y, Tian YH, Sun XY, Zhang GY, Li QP, Xu XY, Li JY, Zhang J. Lessons on malaria control in the ethnic minority regions in Northern Myanmar along the China border, 2007-2014. Infect Dis Poverty 2016; 5: 95.

49. Xu JW, Liu H, Zhang Y, Guo XR, Wang JZ. Risk factors for border malaria in a malaria elimination setting: a retrospective casecontrol study in Yunnan, China. Am J Trop Med Hyg 2015; 92:
546-551.

50. Al Zahrani MH, Omar AI, Abdoon AMO, Ibrahim AA, Alhogail A, Elmubarak M, Elamin YE, AlHelal MA, Alshahrani AM, Abdelgader TM, Saeed I, El Gamri TB, Alattas MS, Dahlan AA, Assiri AM, Maina J, Li XH, Snow RW. Cross-border movement, economic development and malaria elimination in the Kingdom of Saudi Arabia. BMC Med 2018; 16: 98.

51. Panvisavas S. Poverty and malaria: A study in a Thai-Myanmar border area. Southeast Asian J Trop Med Public Health 2001; 32: 608-614.

52. Tang L. Malaria in China: from control to elimination. Int J Med Parasit Dis 2009; 36: 258-265.

53. Nkegbe PK, Kuunibe N, Sekyi S. Poverty and malaria morbidity in the Jirapa District of Ghana: A count regression approach. Cogent Econ Finance 2017; 5: 1293472. 